\title{
ON THE ORIGIN OF BULLET GRYSTALS AT THE SOUTH POLE
}

\author{
By Anthony J. Gow \\ (U.S. Army Cold Regions Research and Engineering Laboratory, Hanover, New Hampshire, \\ U.S.A.)
}

\begin{abstract}
An examination of bullet crystals in precipitation at the South Pole indicates that combinations of bullets originate as primary growth structures and that individual bullets are formed as a result of the disintegration of these primary growth forms rather than by independent crystallization of pyramidally terminated columns.

RÉsumé. Sur l'origine des cristaux cylindro-ogivales au Pole Sud. L'examen des cristaux cylindro-ogivales dans les précipitations au Pôle Sud indique que des "combinaisons de cristaux" ont leur origine dans les structures primaires de croissance et que les cristaux cylindro-ogivales individuels sont formés comme résultat de la désintégration de ces formes primaires de croissance plutôt que d'une cristallisation indépendante de colonnes terminées en pyramide.
\end{abstract}

Zusammenfassung. Úber die Entstehung von "Geschoss"-Kristallen am Südpol. Eine Untersuchung von Geschoss-Kristallen im Niederschlag am Südpoll zeigt, dass Kombinationen von Geschossen aus primären Wachstumsstrukturen herstammen und dass einzelne Geschosse eher das Ergebnis des Zerfalls solcher primärer Wachstumsformen als der unabhängigen Kristallization von pyramidenartig begrenzten Säulen sind.

\section{INTRODUCTION}

Very light precipitation in the form of "diamond dust" occurs regularly throughout the summer at the South Pole. Even on cloudless days the glint of minute crystals can readily be observed. On 22 December I96r an unusually heavy fall of ice crystals took place. The crystals were larger than usual and the precipitation was dense enough to form an ice fog. A prominent $22^{\circ}$ halo was observed around the sun. The weather at the time was calm and cold with a surface temperature of $-25^{\circ} \mathrm{C}$. Two samples of falling ice crystals were collected an hour apart on a velveteen sheet, and were then transferred onto glass slides and photographed at $-\mathrm{I} 5^{\circ} \mathrm{C}$. with a Bausch and Lomb extension camera. Both single and composite forms of ice crystal were observed. Some typical examples of each are shown in Figures I and 2. The precipitation consisted entirely of simple crystal forms, including columnar crystals, bullets (columns conically terminated at one end), minute hexagonal plates, and spatial dendritic plates. These forms of crystals are typically developed at low temperatures and low moisture contents. Also, the formation of a $22^{\circ}$ halo seems to be diagnostic of this assemblage of ice crystals. At Maudheim, Antarctica, for instance, Liljequist (1956) noted that when only the $22^{\circ}$ ring was observed, the precipitation was invariably composed of compound bullets and other composite crystals. Although simple columns formed the largest crystals (up to $\mathrm{I} \cdot \mathrm{o} \mathrm{mm}$. long) at the South Pole, bullets and combinations of bullets predominated. Bullettype crystals were rarely longer than $0.4 \mathrm{~mm}$., but they were found to exist in a variety of shapes. These included relatively bluntly terminated crystals as well as pointed daggerlike crystals. Some crystals were typically bullet-shaped with well rounded, symmetrical heads, e.g. Figure Ie, but most crystals possessed distinctly asymmetrical terminations. Although combinations of three or more bullets were invariably joined together at their heads, the component crystals were not always the same size and their heads could be variously shaped. The tail ends of a number of crystals were observed to be hollow (Fig. 2c) but others appeared to be quite solid.

\section{Observations and Discussion}

It is generally assumed that bullets are derived from prismatic columns terminated at one end only by plane pyramid faces. For example, according to Nakaya (1954, p. 5o) "the bullet type means a column with a pyramidal head like a rock crystal". The existence 
of pyramid faces in the crystallographic sense is clearly implied here, ${ }^{*}$ yet with the possible exception of one very small crystal (Fig. Im) plane pyramid faces were not observed on any of the bullets at the South Pole. A careful scrutiny of photographs of bullet crystals in Nakaya also failed to reveal any definite traces of pyramid faces. Pyramid crystals were apparently described for the first time by Scoresby $(1820)$ but there seems to have been few authenticated

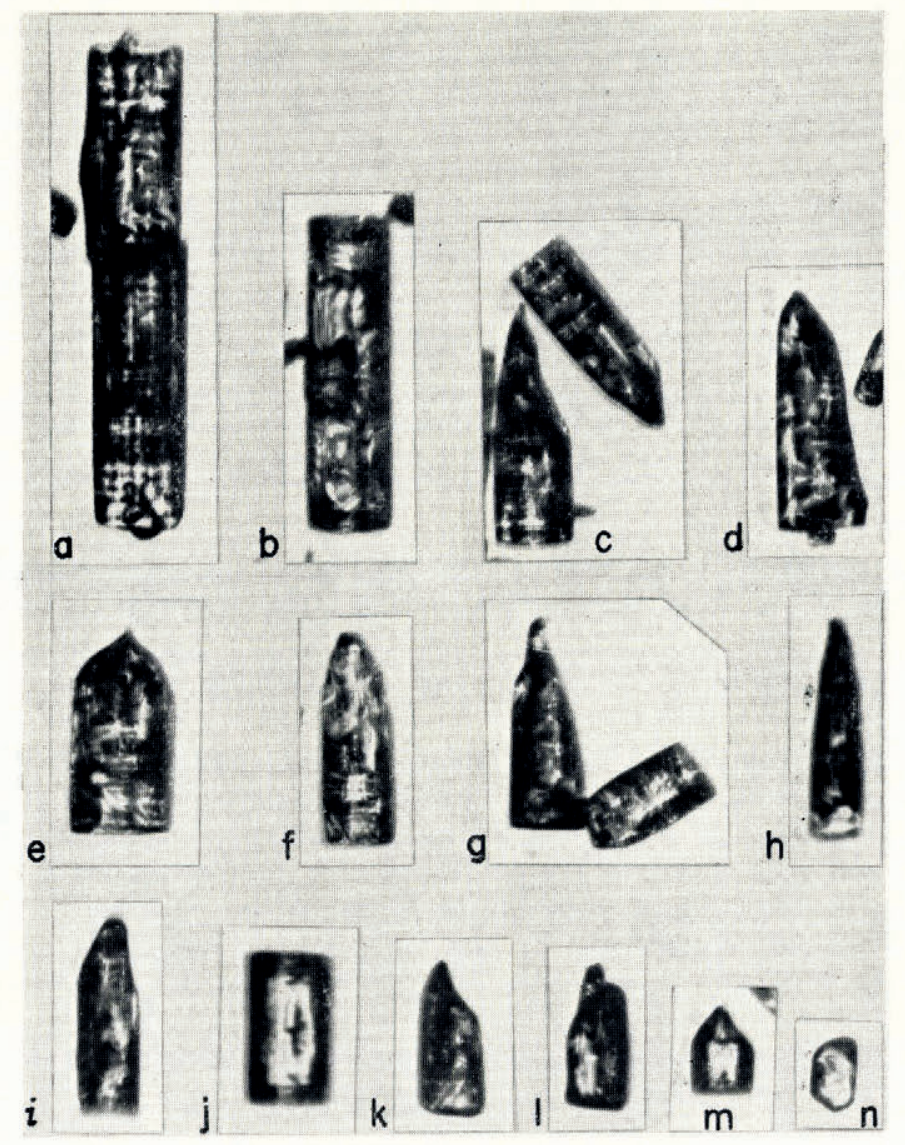

Fig. I. Examples of individual ice crystals observed in precipitation at the South Pole. This collection was made on 22 December I96r. Bullet crystals are predominant. Note the generally asymmetrical shapes of these bullets. The very symmetrical crystal $(e)$ is particularly interesting in that the tip end of this crystal displays a distinctive reversal of curvature - a mosque-form bullet. The columnar crystals $(a$ and $b$ ) both appear to be twinned on the basal plane. Some off-set is apparent in $(a)$. Crystal $(m)$ may be terminated by pyramid faces. This was the only crystal of its type observed in samples from the South Pole. Magnification $50 \times$

observations of such crystals since, in either natural snow or artificially formed ice crystals. Shaw and Mason (1955) recognized prisms terminated at one end by a pyramid among crystals grown on a chilled metal plate, but the conditions of growth were thought not to simulate satisfactorily those in the free atmosphere. In a subsequent experiment Hallett and Mason (1958) used a diffusion cloud chamber to grow a variety of crystals at various temperatures and supersaturations. With this apparatus, it appears they were able to grow all the major forms of ice crystals except bullet crystals. However, they make no mention of having

* See also Nakaya (1954, p. 81 and p. 86) on classification of bullets. 
observed the growth of pyramid crystals in these experiments. The apparent scarcity of hemimorphic forms in both naturally and artificially formed snow crystals might indicate that pyramidally terminated crystals are not really essential to the formation of bullets, or combinations of bullets. In any case, the characteristically rounded and frequently asymmetrical nature of the heads of bullet crystals must surely be attributable to sublimation effects. These

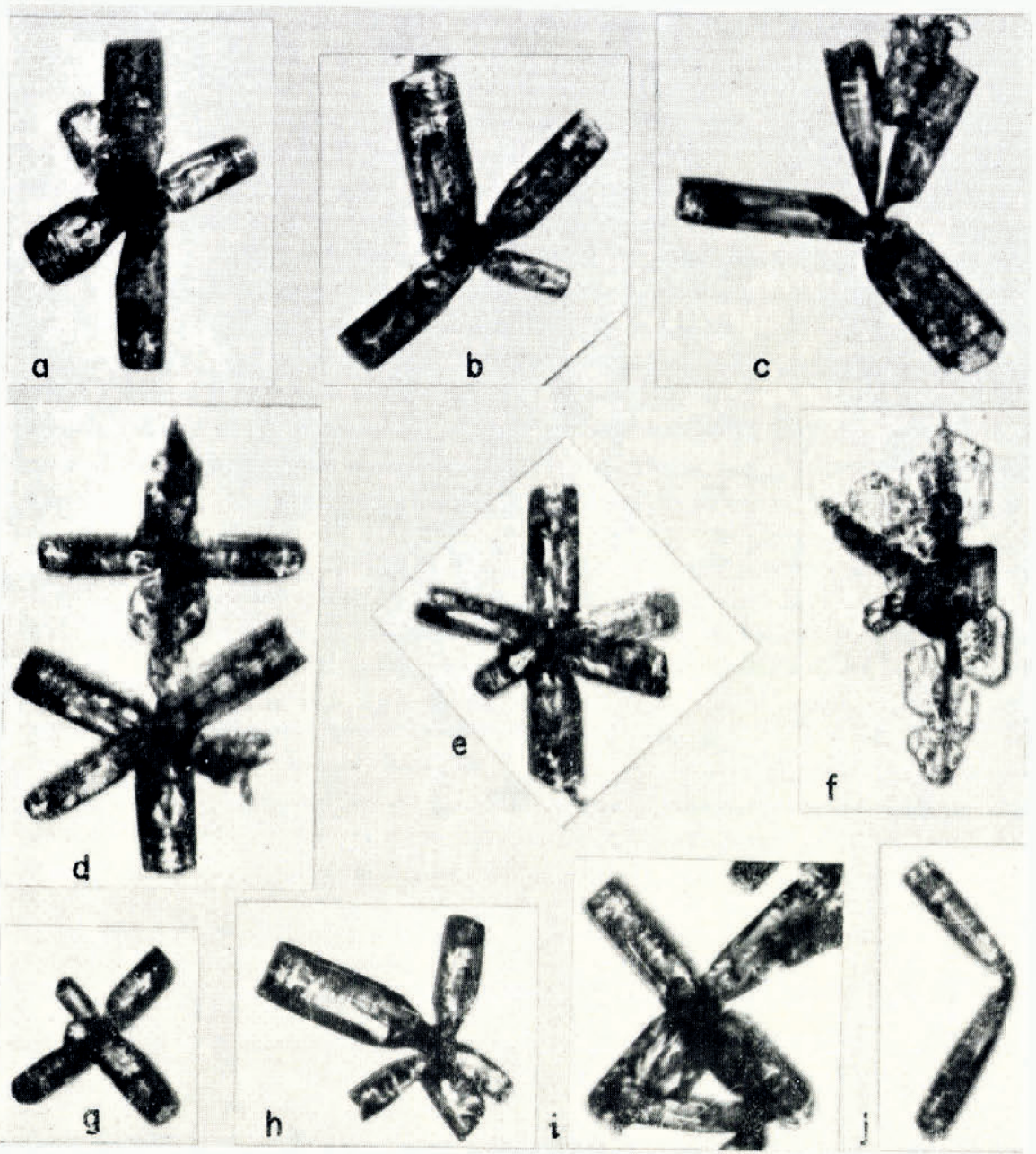

Fig. 2. A representative collection of composite crystals. Three-dimensional (e), as well as two-dimensional cruciform structures can be observed. The effects of sublimation are apparent in most combinations of bullets. Note the especially fragile appearance of $(c)$; also the cavity in the tail of the largest bullet and the variations in the shapes of the other component crystals. Magnification $50 \times$

effects are most strikingly developed in combinations of bullets (Fig. 2). Nakaya (1954, p. 53) apparently believes that these compound forms are formed by an actual gathering together at their heads of two or more separately crystallized bullets. It is true that in the great majority of combinations the component bullets are joined at their heads but this does not necessarily mean that they were formed by mechanical aggregation of pre-existing bullet crystals. In fact, most of the available evidence would seem to point to the contrary; that combinations of bullets originate as primary growth structures and that individual bullets are formed by the 
disintegration of these primary growth forms. Apart from these there seem to be very few other types of composite structure among bullets. Obvious accidental attachments of columns and prisms are occasionally observed but the widespread occurrence of symmetrically coalesced bullets can hardly be attributed to accident. Also, considering the low temperatures at which these crystals were formed at the South Pole and the subsequent difficulty that colliding crystals would experience adhering to one another, it is perhaps surprising even to find combinations of two crystals, let alone combinations of up to six symmetrically aggregated bullets. Even if supposed polar properties were involved (see Rossmann, 1948) it is not immediately apparent why combinations of bullets joined at their heads should form to the complete exclusion of other types of combination, e.g. "head to tail" forms.

There is some additional evidence, however, to support the existence of composite growth structures in natural snow crystals. In his discussion of spatial dendritic crystals, Nakaya (1954, p. 48) draws attention to the frequent occurrence of so-called stones at the center of these crystals. Occasionally stones were observed without any accompanying dendritic growth. One such stone composed of a cross-like assemblage of stout prisms is featured in figure I I $4(6$ I6) of Nakaya (1954, p. 49). This structure is thought by Nakaya to represent the initial stage in the growth of a spatial dendritic crystal. The stone presumably formed by the simultaneous growth of several prismatic crystals from a common center. Recent studies by Kumai (1964) of low temperature ice fog in Alaska have revealed the existence of composite particles among the minute ice crystals. Such a seed or compound nucleus could conceivably promote the growth of a radiating cluster of crystals. In fact, the possibility that compound bullets originated in this way is even suggested by Kumai. It is of interest here to note that in a number of combinations from the South Pole the component crystals showed little, if any, trace of bullet-shaped heads. Instead, they appeared to be composed of simple, unsublimated columns; some even have a three-dimensional aspect (Fig. 2e). Such combinations are believed to represent relatively unsublimated primary growth structures. Mason (1963) has indicated that prismatic columns sometimes occur in clusters originating from a central frozen droplet. In support of this Mason reproduces a photograph from Weickmann ( 1948 ) showing clusters of hollow prismatic columns. Mason also makes brief mention of the occasional occurrence of pyramidally terminated crystals in clouds only slightly supersaturated with respect to ice. However, the crystals to which he refers in a second photograph from Weickmann do not seem to demonstrate the hemimorphic aspects very convincingly.

\section{Conclusion}

An examination of ice crystals at the South Pole suggests that bullet crystals originate as clusters of primatic columns attached to some central seed or nucleus. Individual bullets are then formed as a result of the disintegration of this primary growth structure. The disintegration is attributed to a gross weakening of the structure caused by sublimation-evaporation at the center of the cluster of crystals. This evaporation of material in the region of attachment of bullets is also thought to be primarily responsible for the formation of the generally rounded cone-shaped heads of bullets. In some cases, however, part of this curvature may have been inherited from the earliest stages of growth; although the growth form of the bullet is substantially prismatic it is possible that this prismatic crystallization could have been preceded by some form of cup growth initially. This mode of origin of bullets does not require that combinations be formed from independently crystallized bullets, nor does it require the formation in the first place of individual prismatic crystals terminated at one end by pyramids. An examination of the literature reveals little positive evidence for the existence of hemimorphic crystals among bullets, and there seems to be no logical explanation to account for the alleged gathering together of bullets by their heads to the almost complete exclusion of other forms of combination. 


\section{Acknowledgement}

The author wishes to thank Mr. Luiz Aldez, meteorologist in charge at the South Pole during i 962 , for much stimulating discussion on the subject of bullet crystals.

MS. received 22 September 1964

\section{REFERENGES}

Hallett, J., and Mason, B. J. 1958. The influence of temperature and supersaturation on the habit of ice crystals grown from the vapour. Proceedings of the Royal Society, Ser. A, Vol. 247, No. 1251, p. 440-53.

Kumai, M. 1964. A study of ice fog and ice fog nuclei at Fairbanks, Alaska. U.S. Cold Regions Research and Engineering Laboratory. Research Report 150.

Liljequist, G. H. 1956. Special studies. Halo-phenomena and ice-crystals (Maudheim, $71^{\circ} \mathrm{O}^{\prime} \mathrm{S}$., $10^{\circ}{ }_{5} 6^{\prime} \mathrm{W}$.). Norwegian-British-Swedish Antarctic Expedition, 1949-52. Scientific Results (Oslo, Norsk Polarinstitutt), Vol. 2, Pt.
2A, 85p. Mason, B. J. 1963. Ice. (In Gilman, J. J., ed. The art and science of growing crystals. New York, John Wiley and
Sons, Inc., p. 1 1 $19-50$. .)

Nakaya, U. 1 954. Snow crystals. Cambridge, Mass., Harvard University Press.

Rossmann, F. 1948. Uber die Entstehung der Schneeflocken. Zeitschrift für Meteorologie, Bd. 2, Ht. 9. p. 305-08.

Scoresby, W. 1820. An account of the Arctic regions, with a history and description of the northern whale-fishery. Edinburgh, Archibald Constable and Co.; London, Hurst, Robinson and Co. Shaw, D., and Mason, B. J. 1955. The growth of ice crystals from the vapour. Philosophical Magazine, Seventh Ser.,
Vol. 46, No. 374, p. 249-62.

Weickmann, H. K. I948. Ice phase in the atmosphere (Die Eisphase in der Atmosphäre). (Volkenrode R $T$ No. 7 I6.) Feb. 1947. Translated by Mrs. M. G. Sutton. London, G. B. Ministry of Supply. (Library Translation No. 273.) 